\title{
Accelerating Access to Clean Cooking Will Require a Heart-Head-and-Hands Approach
}

\author{
Yabei Zhang ${ }^{1}$ \\ Published online: 19 July 2021 \\ (c) Society for International Development 2021
}

\begin{abstract}
The world is far off track from achieving the UN Sustainable Development Goal (SDG) 7 target for universal access to clean cooking by 2030 owing to a lack of prioritization. Breaking this impasse requires transformative public- and private-sector solutions and large-scale investments that can improve the overall cooking ecosystem with end users' needs at the centre. Recent trends in designing more effective solutions are gaining momentum. By working together with a 'heart-head-andhands approach', stakeholders can move the needle forward on clean cooking, and in the process, contribute to the SDGs for health and well-being, women's empowerment, and a cleaner environment.
\end{abstract}

Keywords Clean cooking interventions $\cdot$ Cooking ecosystem $\cdot$ Modern energy cooking services $\cdot$ Multi-tier framework Sustainable development goals · User-centred context

The world is not on track to meet the 2030 goal of universal access to clean cooking, a key component of achieving Sustainable Development Goal 7 (SDG 7). According to the latest Tracking SDG 7: The Energy Progress Report, 2.6 billion people, about one-third of the global population, still cook with traditional, polluting fuels and technologies (2019 figure) (IEA et al. 2021). Without accelerated action, an estimated 2.4 billion people will remain without clean cooking services in 2030 . The situation is particularly dire in sub-Saharan Africa, where progress on access to clean cooking has not kept pace with population growth. In 2019, about $83 \%$ of that region's population-some 910 million people-lacked access to clean cooking, which is more than for any other region.

The status quo is costing the world more than US\$2.4 trillion each year, driven by the adverse impacts on health (US\$1.4 trillion), climate (US\$0.2 trillion), and women's lost productivity (US $\$ 0.8$ trillion) (ESMAP 2020). In lowand middle-income countries, household air pollution from cooking with traditional stoves and fuels is linked to nearly 4 million premature deaths per year (WHO 2014), mostly women and young children. Women spend several hours

Yabei Zhang

yzhang7@worldbank.org

1 The World Bank, Washington, DC, USA per day on cooking-related tasks, including fuel collection, cooking, and stove cleaning. In terms of climate impacts, greenhouse gas emissions from the unsustainable collection of wood fuels for cooking amount to a gigaton of carbon dioxide $\left(\mathrm{CO}_{2}\right)$ per year, equivalent to about $2 \%$ of global emissions (Bailis et al. 2015), whilst residential solid fuels account for up to $58 \%$ of the world's black-carbon emissions (CCAC 2019).

\section{Why has Progress Lagged?}

Improving access to clean cooking can accrue large socioeconomic and environmental benefits for society. However, progress has been stymied due to a lack of prioritization at all levels, including donors, national governments, the private sector, and households.

Clean cooking is an 'orphan' sector. Even though it cuts across a broad array of sectors-energy, health, environment, climate, gender, social protection, finance, rural and urban development, and private-sector development, amongst others-clean cooking is not prioritized by any of these sectors for large-scale public investment. Clean cooking has long been neglected in national policies and development programmes and has few institutional public-sector champions. 
Clean cooking is also an 'invisible' sector. The groups most affected by the lack of access to clean cookingpoor and rural households, particularly women and children-are often unaware of the adverse health effects of household air pollution. In cases where they are aware, they likely lack a voice in the national policy dialogue. In many poorer countries, traditional intra-household decision-making norms (e.g., women cook and men make large purchasing decisions) or affordability constraints prevent families from prioritizing the adoption of clean cooking solutions. These and other factors have contributed to the sector's invisibility. Indeed, progress toward universal access to clean cooking has advanced more slowly than that for ending poverty.

In addition, clean cooking is perceived as an 'expensive' sector. Households do not internalize the publicgoods benefits from clean cooking in their investment decision-making, especially in rural areas where firewood can be freely collected from the surrounding environment. Also, clean cooking solutions are highly contextual, making it difficult to develop affordable solutions at scale. Due to the lack of profitability, the sector has been unable to attract sizeable private investment.

Today, finance for clean cooking remains far below the amount needed to achieve the SDG 7 target by 2030 . In 2018 , the traceable public and private investment in clean cooking was just US\$131 million (SEforALL 2020), far less than the US $\$ 6$ billion estimated for access to clean cookstoves only (IEA 2021), and less than $0.1 \%$ of the investment required to achieve the highest tiers of modern energy cooking services (ESMAP 2020).

\section{Breaking the Impasse}

Achieving universal access to clean cooking by 2030 will require transformative solutions-both market-based and investment-driven - that improve the overall cooking ecosystem with end users' needs and priorities at the center. Breakthroughs are especially needed in three key interlinked areas: (1) political commitment, (2) investment, and (3) knowledge and innovation. Amongst the three, political commitment is the most important. Past experience shows that tackling the clean cooking challenge cannot rely on the market alone. Rather, it requires that clean cooking become a political, economic, and environmental priority, supported by policies, investments, and multi-sector partnerships. Governments, development partners, donors, and coordinating platforms all play key roles. Driving transformative solutions requires that these stakeholders take a 'heart-head-and-hands' approach, as explained below.

\section{The Heart: Putting People at the Center}

It takes empathy and compassion to understand how people's lives can be adversely impacted by not having access to clean cooking and recognize its value as a key development issue. With this heartfelt understanding, high-level decision-makers will be able to make universal access to clean cooking a political priority and direct attention to the large socioeconomic and environmental returns that can result from improving access. Such an understanding will also enable policy makers to put users at the center of developing and delivering clean cooking solutions. In fact, ever-increasing research confirms that the sustainability of such initiatives depends on designing interventions that are responsive to the needs and experiences of the stove users themselves, taking into account their unique cooking practices and preferences, fuel accessibility constraints, and affordability levels, amongst other diverse cultural and socioeconomic considerations. The economic and social opportunities offered by clean cooking interventions are particularly important for empowering women, youth, and other often marginalized groups. Therefore, for those who cannot afford it, the delivery of clean cooking solutions should be part and parcel of social safety net programmes.

\section{The Head: Developing National Strategies and Roadmaps}

Achieving universal access to clean cooking should be fully and formally integrated into the strategic energy development and planning process and other relevant policies and strategies, such as the National Determined Contributions and COVID-19 recovery plans. The effort needs to be led by a designated institutional champion responsible for coordination with key stakeholders and accountability for achieving results. The cleancooking strategy development and planning process requires stocktaking of the baseline situation on cooking energy demand, supply, and policy environment, combined with lessons and insights learned through review of relevant programs and consultation with a full range of stakeholders. The transition pathways of national roadmaps to universal access should be guided by a least-cost, best-fit strategy that reflects diverse users' needs, local market conditions, and national comparative advantages on energy resources. Through the process, governments can raise awareness amongst key stakeholders, build coalitions and partnerships, and mobilize public and private investments needed to implement the roadmaps.

\section{The Hands: Focusing on Results-oriented Implementation}

Strategy development, planning, and implementation require hands-on practices; learning from doing; and continued 
monitoring, evaluation, and adjustment to achieve better results. Because cooking is a contextualized system, as previously mentioned, there is no one-size-fits-all solution. Although approaches share common barriers, the ones that fit best will vary by location because of differences in behaviour, culture, resources, institutions, and market conditions. Therefore, programme design and implementation should focus on encouraging the development of contextualized solutions and continued innovation for improving access to modern energy cooking services; that is, those that are clean, efficient, convenient, safe, reliable, and affordable. Advancing localized, best-fit approaches, in turn, can lead to realizing the longer-term development co-benefits of adopting clean cooking solutions (e.g., better health, gains in gender equality, and a greener planet).

\section{Trends and Opportunities for Transformative Change}

Recent trends in prioritizing and designing more effective strategies for clean cooking interventions are gaining momentum. Adoption of the SDGs has helped to catalyze an increase in policy prioritization at both the global and country levels. For example, the Health and Energy Platform of Action, launched in 2019, assigns priority to clean cooking. In 2020, the G20 energy ministers endorsed the G20 Initiative on Clean Cooking and Energy Access. ${ }^{1}$ And in June 2021, the High-Level Coalition on Health and Energy, convened by the Director-General of the World Health Organization (WHO), endorsed a Strategic Roadmap on Health and Energy ${ }^{2}$ to promote clean cooking and the electrification of healthcare facilities. Furthermore, more countries have begun to formalize cooking energy demand in their national energy planning and strategies with specific targets. The High-level Dialogue on Energy, ${ }^{3}$ to be convened by the Secretary-General of the United Nations under the auspices of the UN General Assembly in September 2021, expects more governments and stakeholders to prioritize clean cooking through energy compacts.

In addition, new and emerging technologies, business models, and financing mechanisms are enabling solutions that are affordable for many more lower-income households. These include the leveraging of successes in off-grid electrification, using high-efficiency cooking appliances, and

\footnotetext{
${ }_{1}$ https://g20.org/en/media/Documents/G20SS_Energy\%20Minister ial\%20Communique.pdf

${ }^{2}$ https://www.who.int/initiatives/health-and-energy-platform-ofaction/high-level-coalition-on-health-and-energy/strategic-roadmapon-health-and-energy

${ }^{3}$ https://www.un.org/en/conferences/energy2021
}

digital and pay-as-you-go (PAYGo) technologies. Modern Energy Cooking Services (MECS), ${ }^{4}$ a five-year, 40 million Pound programme funded by UK Aid (FCDO), is a good example of how research and innovation funding is being used to address the sector challenge.

Furthermore, the understanding of household cookingenergy needs and sector dynamics is growing thanks to the availability of more in-depth data and research tools. For example, the World Bank's Multi-Tier Framework (MTF) for cooking integrates holistic criteria on end users' needs and preferences, which can be used to track progress and measure impacts (Bhatia and Angelou 2015). The MTF employs a multidimensional, tiered approach for measuring household access to cooking solutions across six contextual and technical attributes: (1) convenience, (2) affordability, (3) safety, (4) fuel availability, (5) exposure, and (6) efficiency. Each attribute is scored across six tiers, ranging from Tier 0 (no access) to Tier 5 (full access). Building on the MTF and household surveys from 71 countries, the State of Access to Modern Energy Cooking Services ${ }^{5}$ report provides an indepth, comprehensive understanding of household cooking energy needs to better inform the development of policies and programme strategies (ESMAP 2020).

Moreover, as more financial resources move in the direction of access to clean cooking, impact-driven forms of financing are gaining ground as a way to pay for the expected public-goods benefits from clean cooking interventions. One such instrument is Results-Based Financing (RBF), which has been demonstrated in other sectors (e.g., health, infrastructure, and education) as an effective tool for using public resources to incentivize the private sector to deliver thirdparty verified results.

The World Bank's Clean Cooking Fund, launched by the Energy Sector Management Assistance Program (ESMAP) at the 2019 UN Climate Action Summit, is using RBF approaches to help countries incentivize the private sector to deliver modern energy cooking services and spur market development. With a five-year funding target of US\$500 million, the Fund's ambition is to catalyze another US\$2 billion in public and private investments to help 200 million people gain access to clean cooking. Specific objectives are to (1) co-finance and leverage concessional finance from the World Bank and attract private-sector investments; (2) catalyze technology and business innovations by providing incentives to players across clean-cooking value chains; and (3) link incentive payments with verified results at the output, outcome, and impact levels, thereby contributing to better health, environmental sustainability, gains in gender

\footnotetext{
4 https://mecs.org.uk/

5 http://documents.worldbank.org/curated/en/937141600195758792/

The-State-of-Access-to-Modern-Energy-Cooking-Services
} 
equality, and inclusive development. The Fund's first IDA co-financed project is in Rwanda. Approved in September 2020 with implementation under way, the project's US $\$ 20$ million clean cooking component is expected to help more than two million people access clean cooking solutions.

The COVID-19 pandemic poses challenges to achieving universal access to clean cooking; however, the recovery efforts could be an opportunity for accelerating the transition. Findings from a recent World Bank case study in rural Kenya show how the pandemic is increasing household preferences for convenience and affordability, whilst magnifying inherent inequalities (Zhang and Li 2021). Middleincome households with less severe affordability constraints are being nudged to switch to modern cooking fuels and technologies, especially biogas and electricity, which have been less disrupted by COVID-19 restrictions. However, for lower-income households, affordability and fuel accessibility remain major barriers to access. As societies recover from the pandemic and rebuild, governments who are leading the efforts can turn challenges into opportunities by including clean cooking as an essential service for all and a critical part of the pandemic response.

\section{Recommended Priority Actions}

Clean cooking must be prioritized as a critical cross-sectoral development issue. Making progress toward the aspirational goal of universal access requires accelerated actions by all stakeholders. Let us imagine the clean cooking ecosystem as a series of concentric circles, with end users at its centre and market shapers, supply- and demand-side actors, and adjacent sectors and development areas situated within the surrounding inner and outer circles. To develop a sustainable clean cooking market, we need to improve the overall ecosystem by raising awareness, enhancing partnerships, harnessing synergies, and monitoring progress with new data and tools. Strengthening the evolving ecosystem requires that our efforts focus on the following, mutually-reinforcing elements that ripple across it:

- Integration Clean cooking for all must be integrated into national policies and planning for energy, climate, and COVID-19 recovery.

- Investments A dramatic scale-up in both public and private investments is needed to implement clean-cooking strategies and action plans to achieve on-the-ground results.

- Innovation Catalysts are needed to spur market innovations that can deliver affordable clean-cooking solutions at scale.

- Impacts Achieving development impacts requires adopting human-centred approaches aligned with both diverse user needs and broader development objectives (e.g., climate, health, gender, jobs, and sustainable livelihoods).

- Inclusiveness The approaches adopted must ensure inclusiveness by addressing the needs of poor, vulnerable, fragile, and displaced populations, as well as engaging and empowering women across the clean-cooking value chains.

Working together with hearts, heads, and hands, we can collectively move the needle forward on clean cooking, and thus contribute to better health for families, women's empowerment, and a cleaner environment.

\section{References}

Bailis, Robert, R. Drigo, A. Ghilardi, and O. Masera. 2015. The carbon footprint of traditional woodfuels. Nature Climate Change 5 (3): 266-272.

Bhatia, Mikul, and Niki Angelou. 2015. Beyond Connections: Energy Access Redefined. Energy Sector Management Assistance Program (ESMAP) Technical Report 008/15. Washington, DC: World Bank.

CCAC (Climate and Clean Air Coalition). 2019. Relation between Short-lived Climate Pollutants and Rural Cooking in the Residential Sector: Prospective Study Applied to Colombia, Mexico, and Peru. https://www.ccacoalition.org/en/resources/relation-betwe en-slcps-and-rural-cooking-residential-sector.

ESMAP (Energy Sector Management Assistance Program). 2020. The State of Access to Modern Energy Cooking Services. Washington, DC: World Bank. http://documents.worldbank.org/curated/en/ 937141600195758792/The-State-of-Access-to-Modern-EnergyCooking-Services.

IEA (International Energy Agency). 2021. Financing Clean Energy Transitions in Emerging and Developing Economies. Paris: International Energy Agency. https://www.iea.org/reports/financingclean-energy-transitions-in-emerging-and-developing-economies.

IEA, Irena, UNSD, World Bank, and WHO (International Energy Agency, International Renewable Energy Agency, United Nations Statistics Division, World Bank, and World Health Organization). 2021. Tracking SDG 7: The Energy Progress Report. Washington, DC: World Bank.

SEforALL (Sustainable Energy for All). 2020. Energizing Finance: Understanding the Landscape 2020. Energizing Finance Research Series, Sustainable Energy for All and Climate Policy Initiative. Vienna: Sustainable Energy for All.

WHO (World Health Organization). 2014. Guidelines for Indoor Air Quality: Household Fuel Combustion. Geneva: World Health Organization.

Zhang, Yabei, and Zijun Li. 2021. COVID-19's Impact on the Transition to Clean Cooking Fuels: Initial Findings from a Case Study in Rural Kenya. Live Wire, 2021/115. Washington, DC: World Bank. https://openknowledge.worldbank.org/handle/10986/35258.

Publisher's Note Springer Nature remains neutral with regard to jurisdictional claims in published maps and institutional affiliations. 